\title{
CT of the hips in the investigation of protrusio acetabuli in Marfan syndrome. A case control study
}

\author{
Rigmor Lundby • Eva Kirkhus • \\ Svend Rand-Hendriksen • John Hald • \\ Are Hugo Pripp • Hans-Jørgen Smith
}

Received: 28 September 2010 /Revised: 10 December 2010 / Accepted: 6 January 2011 /Published online: 14 February 2011

(C) The Author(s) 2011. This article is published with open access at Springerlink.com

\begin{abstract}
Objectives To establish the prevalence of protrusio acetabuli (PA) in adults fulfilling the Ghent criteria for Marfan syndrome (MFS), and in a normal adult population.

Methods 105 adults with probable MFS and 107 controls were included. CT of the hips was obtained. A qualitative assessment of PA was performed. A new method for estimating the degree of PA was introduced with measurement of the parameter CWD (circle-wall distance). Results were compared to an alternative method based on MRI [1]. Results 87 of the study group fulfilled the Ghent criteria of MFS (Ghent positives), and 18 did not (Ghent negatives). PA was diagnosed qualitatively in $74.7 \%$ of Ghent positive persons, in $27.8 \%$ of Ghent negative persons, and in 3.7\% of the controls. CWD was significantly different between the three groups $(p<0.001)$. A slight but significant gender difference was found in Ghent positive persons only. The alternative method did not differentiate between the groups
\end{abstract}

R. Lundby $\cdot$ S. Rand-Hendriksen $\cdot$ H.-J. Smith

Faculty of Medicine, University of Oslo,

Oslo, Norway

R. Lundby $(\bowtie) \cdot$ E. Kirkhus $\cdot$ J. Hald $\cdot$ H.-J. Smith

Department of Radiology and Nuclear Medicine,

Oslo University Hospital, Rikshospitalet,

Sognsvannsvn. 20,

0027 Oslo, Norway

e-mail: rigmor.lundby@medisin.uio.no

S. Rand-Hendriksen

TRS National Resource Centre for Rare Disorders,

Sunnaas Rehabilitation Hospital,

Nesoddtangen, Norway

A. H. Pripp

Biostatistics and Epidemiology Unit, Oslo University Hospital, Oslo, Norway with respect to PA, but showed a significant difference between genders.

Conclusions PA was found significantly more often in MFS persons than in controls. Our method was found to be robust and highly reproducible, giving a direct measurement of pelvic protrusion irrespective of pelvic shape.

Keywords Marfan Syndrome · Computed tomography (CT) $\cdot$ Hip joint $\cdot$ Pelvic bones $\cdot$ Connective tissue diseases

\section{Introduction}

Protrusio acetabuli (PA) is an inward protrusion of the acetabulum as a rounded mass into the pelvis [2]. Pelvic intrusion and acetabular protrusion seem to be used synonymously. The degree of protrusion varies from a few millimetres to five centimetres [2]. PA is seen in different disorders including primary idiopathic cases and secondary to neoplastic, infectious, metabolic, inflammatory, traumatic, congenital and genetic disorders [3].

PA is one of the eight manifestations that may contribute to the major skeletal criterion for Marfan syndrome (MFS) according to the Ghent nosology [4] (Table 1), and is included as one of the features of the "systemic score" in the newly revised Ghent criteria [5].

A number of radiological features of PA have been suggested, but no gold standard has emerged [6-8]. A newly published study concludes that as pelvic tilt increases, classic radiographic measurements of PA become unreliable, and that computed tomography or magnetic resonance (MR) imaging probably will be more reliable [9].

In this case control study the aims were to establish the prevalence of PA in adult persons fulfilling the Ghent criteria 
Table 1 Diagnostic Criteria for Marfan syndrome (MFS) according to the Ghent nosology

\begin{tabular}{|c|c|c|}
\hline System & Major criteria & Criterion for involvement \\
\hline Skeletal & $\begin{array}{l}\text { Requires four of the eight manifestations } \\
\text { listed below } \\
\text { Manifestations: } \\
\text { - Pectus carinatum } \\
\text { - Pectus excavatum requiring surgery } \\
\text { - Reduced upper to lower segment ratio }<0.85 \\
\text { or Arm span to height ratio greater than } 1.05 \\
\text { - Wrist and thumb signs } \\
\text { - Scoliosis of }>20^{\circ} \text { or spondylolisthesis } \\
\text { - Reduced extension at the elbows }\left(<170^{\circ}\right) \\
\text { - Medial displacement of the medial } \\
\text { malleolus causing pes planus } \\
\text { - Protrusio acetabuli of any degree }\end{array}$ & $\begin{array}{l}\text { Requires two of the eight manifestations in the left } \\
\text { column or one manifestation plus two minor criteria } \\
\text { Minor criteria } \\
\text { - Pectus excavatum of moderate severity } \\
\text { - Joint hypermobility (Beighton score } \geq 4 \text { ) } \\
\text { - Highly arched palate with crowding of teeth } \\
\text { - Facial appearance (dolicocephaly, malar hypoplasia, } \\
\text { enopthalmos, retrognathia, down-slanting } \\
\text { palpebral fissures) }\end{array}$ \\
\hline Ocular & Ectopia lentis & $\begin{array}{l}\text { Requires two of the following three minor criteria } \\
\text { Minor criteria } \\
\text { - Abnormally flat cornea }(<41,5 \text { dioptres }) \\
\text { - Increased axial length of the ocular globe }(>23,5 \mathrm{~mm}) \\
\text { - Hypoplastic iris or ciliary body }\end{array}$ \\
\hline Cardiovascular & $\begin{array}{l}\text { - Dilatation of the ascending aorta with or without } \\
\text { aortic regurgitation and involving at least the } \\
\text { sinuses of Valsalva } \\
\text { - Dissection of the ascending aorta }\end{array}$ & $\begin{array}{l}\text { Requires the presence of at least one major criterion or } \\
\text { one minor criterion } \\
\text { Minor criteria } \\
\text { - Mitral valve prolapse with or without mitral valve } \\
\text { regurgitation } \\
\text { - Dilatation of the main pulmonary artery in the absence } \\
\text { of valvular or peripheral pulmonic stenosis or any } \\
\text { other obvious cause below the age of } 40 \text { years } \\
\text { - Calcification of the mitral annulus before the age } \\
\text { of } 40 \text { years } \\
\text { - Dilatation or dissection of the descending thoracic } \\
\text { or abdominal aorta below the age of } 50 \text { years }\end{array}$ \\
\hline Pulmonary & None & $\begin{array}{l}\text { Requires at least one minor criterion } \\
\text { Minor criteria } \\
\text { - Spontaneous pneumothorax } \\
\text { - Apical blebs }\end{array}$ \\
\hline Skin and Integument & None & $\begin{array}{l}\text { Requires at least one minor criterion } \\
\text { Minor criteria } \\
\text { - Striae atrophicae (stretch marks) not associated with } \\
\text { marked weight changes, pregnancy or repetitive stress } \\
\text { - Recurrent or incisional herniae }\end{array}$ \\
\hline Dura mater & $\begin{array}{l}\text { Major Criterion: } \\
\text { - Lumbosacral dural ectasia }\end{array}$ & None \\
\hline Genetic & $\begin{array}{l}\text { - Having a parent, child or sib who meets } \\
\text { these diagnostic criteria independently } \\
\text { - Presence of a mutation in } F B N 1 \text { known } \\
\text { to cause the Marfan syndrome } \\
\text { - Presence of a } F B N 1 \text { haplotype around } F B N 1 \text {, inherited } \\
\text { by descent, known to be associated with unequivocally } \\
\text { diagnosed Marfan syndrome in the family }\end{array}$ & None \\
\hline
\end{tabular}

Confirmation of the diagnosis requires the presence of at least two Major Criteria in two different organ systems and involvement of third organ system. Family history / genetic is counted as an organ system 
for MFS, and to find the best criteria for the assessment of PA. CT was chosen due to its direct visualization of the acetabular shape and its superior depiction of cortical bone.

\section{Materials and methods}

The study was approved by the Regional Medical Ethics Committee.

For the purpose of informed consent only persons aged above 18 years were included.

\section{Study population}

The participants were recruited either by letter sent to the 134 individuals above 18 years of age registered in a National resource centre as having MFS; by advertisement in the journal of the National Association of MFS, or through invitations distributed in the Department of Thoracic and Cardiovascular Surgery at our hospital to patients suspected of having MFS. Age was the only exclusion criterion.

Out of 109 individuals that gave informed consent for participation, one died before the study started; one living abroad was not able to attend, and two withdrew. Consequently, the study population consisted of 105 persons, 67 women aged 20-69 years, mean 41.2 years (SD 13.6), and 38 men aged 19-62 years, mean 35.1 (SD 11.3) years. Before inclusion, 90 had been given a diagnosis of Marfan syndrome; 15 were suspected of having the diagnosis. All participants were Caucasian.

All persons in the study group were assessed for all parts of the Ghent criteria [4] by the same group of physicians. The assessment included sequencing of the entire coding region of the gene FBN1 and search for large deletions or duplications $[10,11]$.

\section{Control population}

The control cases were chosen from the pool of patients in the radiological archive (PACS) of the Department of Radiology, based on the following criteria: Sex- and age-matched asymptomatic persons with respect to the hips and without any known connective tissue disorder, examined by CT of the abdominal and /or pelvic area due to symptoms from the abdominal area or with suspected vessel disease in the pelvic or abdominal region. Patients with liver or kidney transplants were excluded. The controls included 107 subjects, 68 women aged 19-69 years, mean 40.9 years (SD 13.7), and 39 men aged 19-64 years, mean 35.8 (SD 12.1) years.

\section{CT imaging}

Axial CT images with $3 \mathrm{~mm}$ slice thickness were obtained in the study population with a GE Prospeed SX CT system (General Electric Medical Systems, Milwaukee, WI, USA) and with different CT systems in the control population.

Image evaluation

The control and study populations were compared in aggregate. Consensus readings of $75 \mathrm{CT}$ examinations of the study group and 77 of the control group were performed by two radiologists (RL and EK). Both were aware of which persons belonged to the study or control group, but had no further clinical information. Thirty CT examinations from each group were interpreted separately by RL and EK for assessment of interobserver agreement. For those without consensus readings, the average of the two radiologists' measurements were used for quantitative data, and for qualitative assessment of whether PA was present, cases with disagreement were resolved by reevaluation in consensus.

\section{Measurements and definitions}

PA was diagnosed qualitatively when there was an intrapelvic protrusion of the medial pelvic wall at the level of the acetabulum. The minimum thickness of the acetabular wall was also assessed; and the term "single cortex" was applied when only a single layer of cortical bone could be identified on two or more contiguous $3 \mathrm{~mm}$ CT slices (Fig. 1).
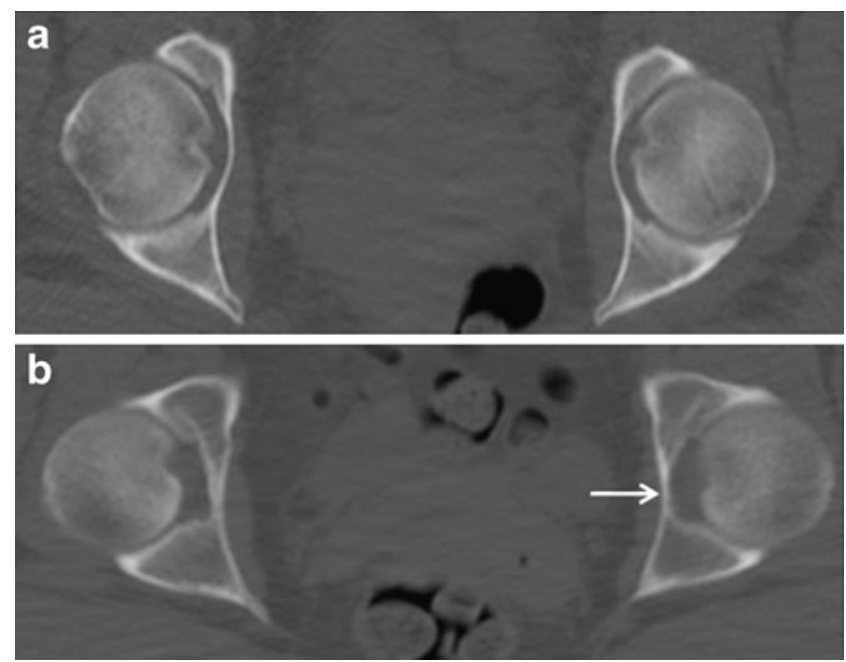

Fig. 1 Axial CT of hips in person with MFS (a) and normal control (b). a Bilateral protrusio acetabuli and only one cortical bone layer, "single cortex". b Normal hips. Single cortex in left hip (arrow) 
For quantification of PA we introduced a circle with $10 \mathrm{~cm}$ radius. The circle was fitted to the inner pelvic wall at the level of the acetabulum where the cranial border of the superior pubic ramus fuses with the anterior column of the acetabulum (Fig. 2). This level usually also includes the fovea of the femoral head. The circle was adjusted to a best fit with the concavities of the inner walls of the anterior and posterior column of the acetabulum. The distance between the line of the circle and the medial most point of the inner pelvic wall of the acetabular fossa (circle-wall distance, CWD) was measured (Fig. 2). A positive distance indicates that this medial most point is medial to the circle, and a negative distance that the inner acetabular wall extends lateral to the circle. Increasing degrees of PA have increasing positive values of CWD.

Quantification of PA was also done according to the method described by Chen et al. [1]. In compliance with this method, the "distance between the medial most point of the acetabular fossa and a line perpendicular to the horizontal axis that passes through the lateral most point of the posterior inner pelvic wall" was measured at the level of the ischial spine. We named this distance the "fossa-line distance" (FLD). For easier comparison of the two methods, we decided to let positive values indicate PA, in contrast to Chen et al. who used negative values to indicate protrusion.

\section{Statistics}

Continuous data were described as mean and standard deviation or median, interquartile range and range for

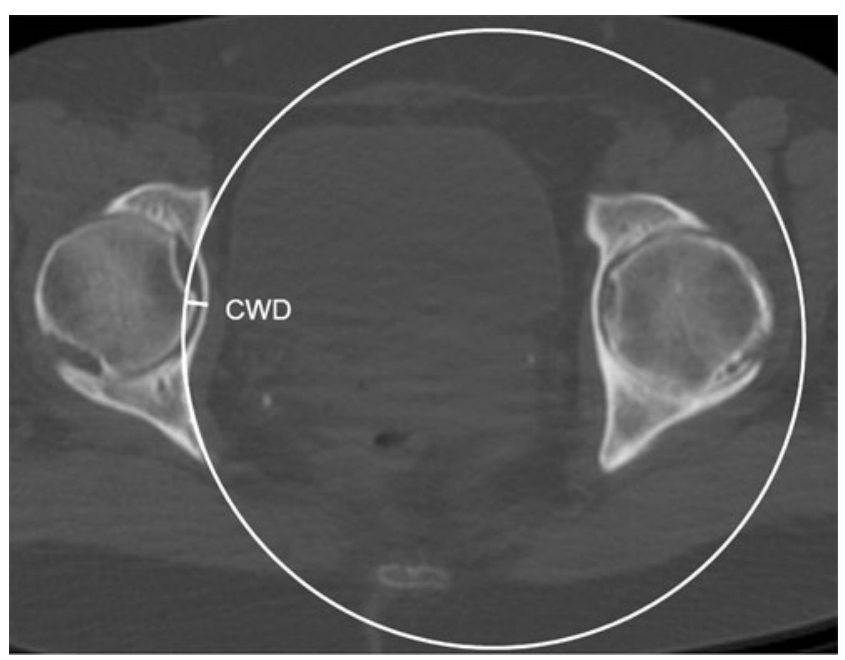

Fig. 2 Axial CT of hips in a case of MFS with bilateral PA. A $10 \mathrm{~cm}$ radius circle is adapted to the inner acetabular wall of the right hip, and measurement of CWD is indicated. Osteoarthritis in left hip normally distributed or skewed data, respectively. Categorical data were described as frequency and percentage. Differences between the study groups were analyzed with one-way ANOVA with post hoc multiple comparison using Bonferroni correction or Pearson chi-square tests as appropriate. Skewed data were analyzed with a nonparametric Kruskal-Wallis test. Interobserver agreement was evaluated with intraclass correlation coefficient for continuous data and kappa statistics for categorical data. Receiver operating characteristic (ROC) curves were constructed to assess the ability of CWD to differentiate MFS from controls and PA from normal hips. Significance level was set to $5 \%$. All statistical analyses were performed by SPSS version 16.0 (SPSS, Chicago, Il).

\section{Results}

The study population was divided into two groups through the clinical assessment for MFS: 1) persons fulfilling the Ghent criteria (Ghent positive, $n=87$ ), and 2) persons suspected of having MFS, but not fulfilling the Ghent criteria (Ghent negative, $n=18$ ). The control population constituted the third group $(n=107)$.

PA was diagnosed qualitatively on one or both sides in $74.7 \%$ of Ghent positive persons, in $27.8 \%$ of Ghent negative persons, and in $3.7 \%$ of the controls (Table 2). None of the participants were dependent on a diagnosis of PA to become Ghent positive. PA, when present, was bilateral in $81.5 \%$ of Ghent positive persons, in $100 \%$ of Ghent negative persons, and in $50 \%$ of controls.

Quantitative assessment of acetabular protrusion using the $10 \mathrm{~cm}$ circle was possible in all study persons and controls. Measurement of CWD showed statistically significant differences between the three groups (Table 2). The median CWD was $3 \mathrm{~mm}$ (range $0.0-9.0 \mathrm{~mm}$ ) in Ghent positive persons, $0 \mathrm{~mm}$ (range $-0.5-5.0 \mathrm{~mm}$ ) in Ghent negative persons, and $0 \mathrm{~mm}$ (range $-3.0-2.0 \mathrm{~mm}$ ) in controls. ROC analysis of CWD vs. qualitative diagnosis of PA showed an area under the curve of 0.99 (95\% CI 0.98-1.0); a CWD cut-off value of $1.25 \mathrm{~mm}$ resulted in a sensitivity and specificity for PA of $95.5 \%$ and $97.6 \%$, respectively. ROC analysis of CWD in differentiating MFS from controls showed a sensitivity and specificity in diagnosing MFS of $68.8 \%$ and $97.2 \%$, respectively, when using a CWD cut-off value of $1.25 \mathrm{~mm}$ (Fig. 3).

Measurement of acetabular protrusion according to Chen et al. [1] was possible in $146(68.9 \%)$ of all study persons and controls. No statistically significant differences between the three groups were found. The median FLD was $0.0 \mathrm{~mm}$ (range $-7.0-8.0 \mathrm{~mm}$ ) in Ghent positive persons, $0.25 \mathrm{~mm}$ (range $-3.0-3.0 \mathrm{~mm}$ ) in Ghent negative persons, and $0.0 \mathrm{~mm}(-7.0-6.0 \mathrm{~mm})$ in controls. 
Table 2 Characteristics of the Ghent positive persons, Ghent negative persons, and controls, in total 212 persons and 420 assessable hips (4 total hip prostheses)

\begin{tabular}{|c|c|c|c|c|}
\hline Characteristics & Ghent positives & Ghent negatives & Controls & $P$ value \\
\hline No. of hips (persons) & $170(87)$ & $36(18)$ & $214(107)$ & \\
\hline Age $[$ mean $(\mathrm{SD})]$ & $39.6(13.0)$ & $36.1(13.4)$ & $39.0(13.3)$ & 0.592 \\
\hline Females $[\mathrm{n}(\%)]$ & $56(64.4 \%)$ & $11(61.1 \%)$ & $68(63.6 \%)$ & 0.966 \\
\hline $\begin{array}{l}\text { PA qualitative method, number (percent) } \\
\text { of group }\end{array}$ & $65(74.7 \%)$ & $5(27.8 \%)$ & $4(3.7 \%)$ & $<0.001$ \\
\hline PA qualitative method, number (percent) of hips & $116(68.2 \%)$ & $10(27.8 \%)$ & $6(2.8 \%)$ & $<0.001$ \\
\hline Single cortex, number (percent) of hips & $159(93.5 \%)$ & $25(69.4 \%)$ & $109(50.9 \%)$ & $<0.001$ \\
\hline $\begin{array}{l}\text { CWD, Circle method on hips, mm } \\
{[\text { median (min, max)] }}\end{array}$ & $3.0(0.0,9.0)$ & $0.0(-0.5,5.0)$ & $0.0(-3,02.0)$ & $<0.001$ \\
\hline FLD, Chen method on hips, mm [median (min, max)] & $0.0(-7.0,8.0) n=116$ & $0.25(-3.0,3.0) n=20$ & $0.0(-7.0,6.0) n=144$ & 0.322 \\
\hline
\end{tabular}

If $\mathrm{n}$ is specified in a cell, the number of hips included in that measurement is different from the number included in the study. $P A$ protrusio acetabuli, $C W D$ circle-wall distance, FLD fossa-line distance

Statistically significant differences between women and men were found in all three groups when using the Chen method (Fig. 4). Median FLDs in women and men, respectively, were 1.0 and $0.0 \mathrm{~mm}$ in Ghent positive persons; 1.0 and $-2.0 \mathrm{~mm}$ in controls. Relatively large positive values of FLD could be found in women also in the absence of PA (Fig. 5).

With our circle method, significant gender differences were not found, except for the Ghent positive persons where women had slightly larger median CWDs than men (3.0 vs. $2.0 \mathrm{~mm}$ ).

"Single cortex" was found on at least one side in $94.3 \%$ of Ghent positive persons, in $83.3 \%$ of Ghent negative persons, and in $57 \%$ of the controls. When presence of "single cortex" was calculated as percentage of number of hips, the figures for these three groups were $93.5 \%, 69.4 \%$,

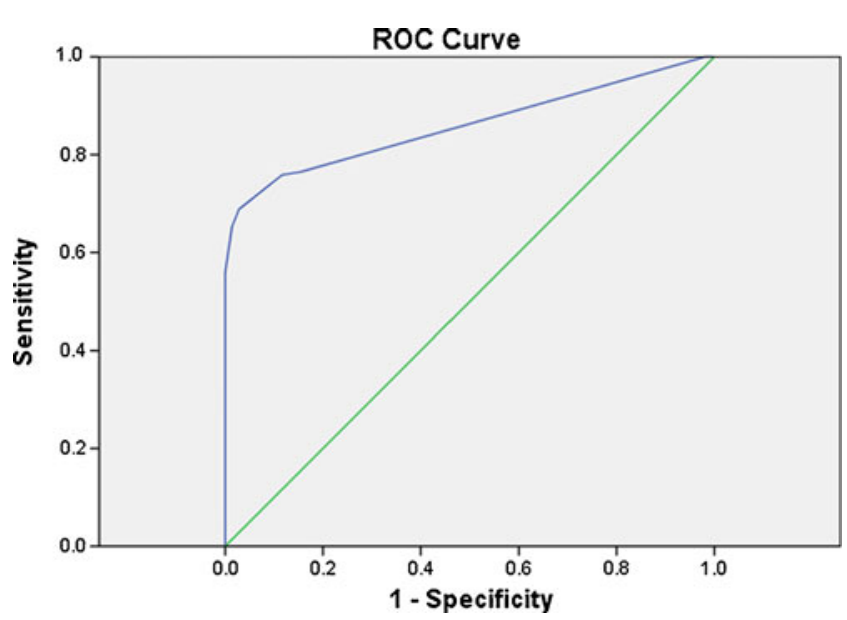

Fig. 3 ROC curve of CWD as a marker of MFS when comparing Ghent positive patients and controls and $50.9 \%$, respectively. These differences between the groups were statistically significant (Table 2).

Interobserver study

The interobserver agreement for assessing PA qualitatively was high with a kappa value $(\mathrm{K})$ of $0.88(95 \%$ CI 0.81 0.95 ) for the right hip and 0.92 (CI $0.81-1.0)$ for the left hip. The circle method had an interclass correlation coefficient (ICC) of 0.91 (95\% CI $0.89-0.95)$ and 0.89 (95\% CI $0.81-0.93$ ) on the right and left side, respectively. For the Chen method, ICC was 0.95 (95\% CI 0.91-0.97) and 0.94 (95\% CI $0.90-0.97)$ on the right and left side, respectively. The kappa value $(\mathrm{K})$ for assessment of single cortex was 0.84 (CI 0.69-0.99) for the right hip and 0.83 (CI 0.67-0.99) for the left hip.

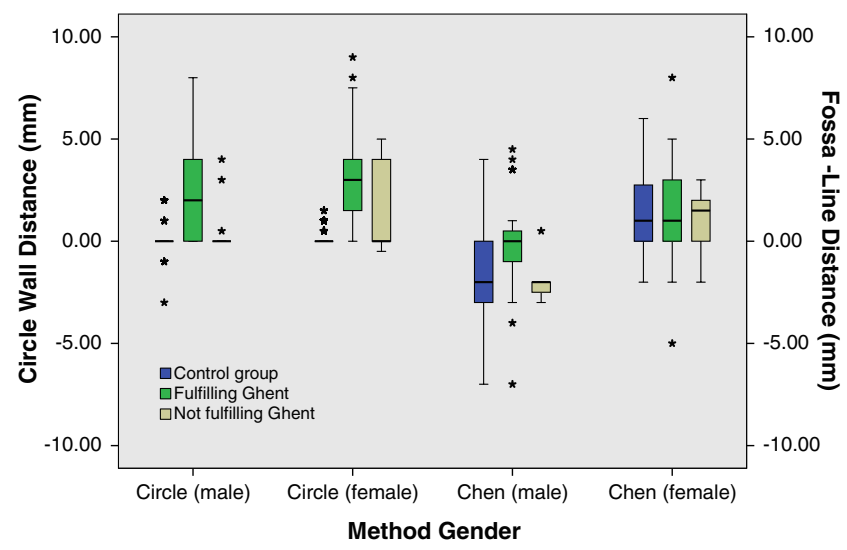

Fig. 4 Boxplots showing median, interquartile distance and range of circle-wall distance (CWD) measured with Circle method and fossaline distance (FLD) measured with Chen's method [1], for males and females, respectively 


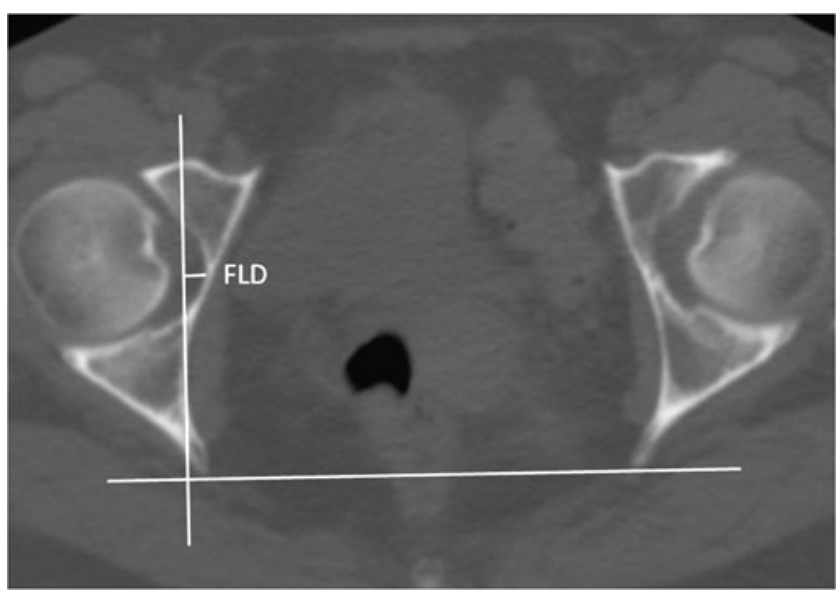

Fig. 5 Axial CT of the hips in female control. Relatively large FLD $(5.5 \mathrm{~mm})$, but no protrusio acetabuli. Lines drawn according to method by Chen et al [1]

\section{Discussion}

PA is one of the manifestations that may contribute to the diagnosis of MFS [4], however, diagnosing PA has been a point of discussion since the accuracy of measurements on plain pelvic radiographs is uncertain and may vary with pelvic tilt [9]. Few authors have assessed the different radiological methods in a validated way [9], and the definition of PA has varied depending on the radiological method used [8].

The reported prevalence of PA in MFS has varied in different studies [7]. Steel et al. studied PA in children and adults with MFS and found different percentages of PA depending on the method of assessment; Steel's method [12] gave $27 \%$ of the patients the diagnosis of PA while the Armbuster method [13] gave $16 \%$. Yule et al. [6] found that $60 \%$ of their MFS patients had PA using the relationship of the acetabular line to the ilioischial line as the sole criterion of PA. In their study, $7 \%$ of the controls had PA based on this method.

Qualitative assessment of PA in our study was defined as any degree of intrapelvic protrusion of the medial pelvic wall at the level of the acetabulum. Using this criterion, we found a very high percentage of PA in our MFS persons (74.7\%) as compared to the controls (3.7\%). The finding of PA in $27.8 \%$ of the persons suspected of having MFS but not fulfilling the Ghent criteria, probably reflects that several of these persons had other connective tissue diseases that might predispose for PA. Of the 18 persons, five had Loeys-Dietz syndrome; one vascular EhlersDanlos syndrome, and one homocystinuria [11].

For quantitative assessment of differences in medial protrusion of the acetabulum we developed the "circle method" with a standard radius. The method was quick and easy to apply, with a high interobserver reproducibility. We found a $10 \mathrm{~cm}$ radius circle to have an arc similar to the concavity of the inner pelvic wall at the acetabulum in most normal adults. The vast majority of the controls therefore had no distance between the circle and the medial pelvic wall at this level, i.e. a CWD of $0 \mathrm{~mm}$. A threshold value for CWD with respect to PA occurs when the inner pelvic acetabular wall is flat. The actual CWD in these cases will vary slightly with the anteroposterior size of the acetabulum, i.e. with the distance between the two points where the circle crosses the acetabular wall anteriorly and posteriorly. We found this distance to be in the order of $3-3.5 \mathrm{~cm}$, corresponding to a CWD of 1.1-1.5 mm. Our ROC analysis suggested a cut-off value of $1.25 \mathrm{~mm}$.

Measurement of CWD with our circle method confirmed a statistically significant difference between the three groups, PA being both more frequent and more severe in Ghent positive persons, with a maximum CWD of $9.0 \mathrm{~mm}$ as compared to $5.0 \mathrm{~mm}$ and $2.0 \mathrm{~mm}$ in Ghent negative persons and controls, respectively. Due to the fact that approximately $25 \%$ of the Ghent positive persons did not have PA, CWD was not a very sensitive marker of MFS (Fig. 3). The less than $100 \%$ specificity with the optimum cut-off value of CWD reflects the finding that even presumed normals may have a slight degree of PA.

The quantitative method for assessment of PA as described by Chen et al. [1] could be applied in approximately two thirds of the cases, the main reason for failure being considerable asymmetry and pelvic tilt. Chen's method requires that the ischial spine is depicted in the same axial image as the medial most point of the acetabular fossa, and this was often not the case. When the method could be used, it had a high interobserver reproducibility, but a low accuracy in detecting PA. Somewhat unexpectedly, Chen's method showed significant gender differences not shown by our circle method (except in the Ghent positive persons). This may be explained by a difference in pelvic shape between genders. The pelvic outlet in women tends to be wider than in men, resulting in a higher degree of convergence of the anterior pelvic walls. In addition, women have increased backward sacral tilt compared to men [14], which will enhance anterior convergence. A high anterior convergence can make the acetabulum project medial to the inner pelvic wall of the posterior column (Fig. 5), giving a false impression of PA.

Our circle method is not influenced by anterior convergence of the pelvic walls, and the slight gender difference in CWD found with this method in Ghent positive persons, may therefore reflect a real difference between the sexes with respect to development of PA in MFS.

We found bilateral PA more often in Ghent positive persons than in the controls, probably reflecting that MFS is a systemic disorder which is likely to affect both hips with the same frequency.

The finding of "single cortex" for the acetabulum was always present in cases of PA. It seems likely that the same 
mechanism that leads to inward protrusion of the acetabular wall also will result in thinning of the wall. "Single cortex" was however observed also in hips without PA as more than half of our normal controls (57\%) had "single cortex" of the acetabulum, but in a smaller part of the acetabular wall compared to hips with PA (Fig. 1).

Our study has several limitations. The choice of a $10 \mathrm{~cm}$ radius circle for measuring the degree of protrusion was somewhat arbitrary, adjusted to the concavity of the inner acetabular wall of most adult hips. This inner concavity is not always uniform; the curvature of the arc may change from anterior to posterior. In cases of PA, when the circle crosses the inner pelvic acetabular wall at two points, the value of CWD is not only dependent on the degree of PA, but also on the distance between the crossing points, which again is determined by the placement of the circle. Our interobserver study indicates, however, that placement of the circle and measurement of CWD could be done with high reproducibility. Using a somewhat larger circle in adults would have had minor influence on the results. Replacing the $10 \mathrm{~cm}$ circle with e.g. a $12 \mathrm{~cm}$ circle would have changed the threshold values of CWD (a flat inner pelvic acetabular wall) from 1.1$1.5 \mathrm{~mm}$ (see above) to $1.0-1.3 \mathrm{~mm}$. A smaller circle would have to be used for similar measurements in children. When testing a new method for accuracy, it should ideally be compared to an independent and established gold standard. In this case, there was no such gold standard, and the sensitivity and specificity of the circle method in diagnosing PA, was therefore calculated using qualitative assessment of PA with $\mathrm{CT}$ as gold standard.

CT of the hips can be performed with low radiation dosage, but persons with hereditary connective tissue diseases are often subject to diagnostic procedures, and methods using ionizing radiation should be kept to a minimum. MR imaging would probably have given similar results with respect to assessment of PA.

\section{Conclusions}

PA was found significantly more often in MFS persons than in controls. Our circle method was found to be robust and highly reproducible, giving a direct measurement of the degree of pelvic protrusion irrespective of pelvic shape. CT gives an excellent view of the hips, and should be preferred to radiography in the diagnosis of PA.

Acknowledgement We thank Finn G. Lilleås, MD, Curato, for his contribution to this work.
Open Access This article is distributed under the terms of the Creative Commons Attribution Noncommercial License which permits any noncommercial use, distribution, and reproduction in any medium, provided the original author(s) and source are credited.

\section{References}

1. Chen L, Boonthathip M, Cardoso F, Clopton P, Resnick D (2009) Acetabulum protrusio and center edge angle: new MR-imaging measurement criteria-a correlative study with measurement derived from conventional radiography. Skeletal Radiol 38:123129

2. Pomeranz MM (2007) Intrapelvic protrusion of the acetabulum (Otto pelvis) (1932) Clin. Orthop Relat Res 465:6-15

3. McBride MT, Muldoon MP, Santore RF, Trousdale RT, Wenger DR (2001) Protrusio acetabuli: diagnosis and treatment. J Am Acad Orthop Surg 9:79-88

4. De Paepe A, Devereux RB, Dietz HC, Hennekam RC, Pyeritz RE (1996) Revised diagnostic criteria for the Marfan syndrome. Am J Med Genet 62:417-426

5. Loeys BL, Dietz HC, Braverman AC, Callewaert BL, De BJ, Devereux RB, Hilhorst-Hofstee Y, Jondeau G, Faivre L, Milewicz DM, Pyeritz RE, Sponseller PD, Wordsworth P, De Paepe AM (2010) The revised Ghent nosology for the Marfan syndrome. J Med Genet 47:476-485

6. Yule SR, Hobson EE, Dean JC, Gilbert FJ (1999) Protrusio acetabuli in Marfan's syndrome. Clin Radiol 54:95-97

7. Van deVelde S, Fillman R, Yandow S (2006) Protrusio acetabuli in Marfan syndrome. History, diagnosis, and treatment. J Bone Joint Surg Am 88:639-646

8. Armbuster TG, Guerra J Jr, Resnick D, Goergen TG, Feingold ML, Niwayama G, Danzig LA (1978) The adult hip: an anatomic study. Part I: the bony landmarks. Radiology 128:1-10

9. Richards PJ, Pattison JM, Belcher J, Decann RW, Anderson S, Wynn-Jones C (2009) A new tilt on pelvic radiographs: a pilot study. Skeletal Radiol 38:113-122

10. Rand-Hendriksen S, Tjeldhorn L, Lundby R, Semb SO, Offstad J, Andersen K, Geiran O, Paus B (2007) Search for correlations between FBN1 genotype and complete Ghent phenotype in 44 unrelated Norwegian patients with Marfan syndrome. Am J Med Genet A 143A:1968-1977

11. Rand-Hendriksen S, Lundby R, Tjeldhorn L, Andersen K, Offstad J, Semb SO, Smith HJ, Paus B, Geiran O (2009) Prevalence data on all Ghent features in a cross-sectional study of 87 adults with proven Marfan syndrome. Eur J Hum Genet 17(10):1222-30, Epub 2009 Mar 18

12. Steel HH (1996) Protrusio acetabuli: its occurrence in the completely expressed Marfan syndrome and its musculoskeletal component and a procedure to arrest the course of protrusion in the growing pelvis. J Pediatr Orthop 16:704-718

13. Sponseller PD, Jones KB, Ahn NU, Erkula G, Foran JR, Dietz HC III (2006) Protrusio acetabuli in Marfan syndrome: age-related prevalence and associated hip function. J Bone Joint Surg Am 88:486-495

14. Soames RW (1995) Skeletal System, p. 674. In: Gray H (ed) Gray's anatomy. The anatomical basis of medicine and surgery, Churchill Livingstone, Edinburgh, London, New York, Philadelphia, Sydney, Toronto 